\title{
Study on the Cultivation of Translators in the Development of Localization Industry
}

\author{
Xiaoru Yang \\ School of Foreign Studies,Xi'an University \\ Xiaoru126@126.com
}

Keywords: Localization Industry, Translators, Cultivation of Translators, International Trade

\begin{abstract}
With the rapid development of the global economy, multinational companies began to invest abroad, thus causing the rise of the localization industry. In the process of international trade, different countries need to overcome the language barriers to make deal, which make translators become a key link in the trade. Localization industry is the result of global economic integration, but also a good tool to improve the market competitiveness of the enterprise. Meanwhile, the cultivation of translators is an important content to enhance the local industry, so that it is necessary to elaborate for this content. After states the concept of localization industry, the development prospects and significance of domestic localization industry, this paper begin to study the training strategy of translators based on the current situation of domestic translation of colleges and universities.

"The Belt and Road" economic policy put forward by China has promoted the friendly exchanges between China and the West Asia and provided a good opportunity for economic integration. Language has become a big obstacle both in the process of international exchange and competition in the market. Therefore, enterprises pay great attention to the cultivation of translators for the orderly development. In particular, the current local competition strategy, more and more enterprises to join the process of localization, in order to better achieve the development of enterprises, attention to translation talent has become an important corporate strategy. In order to achieve a better development, more and more enterprises join the process of localization. Besides, pay attention to the cultivation of translator become an important business strategy.
\end{abstract}

\section{The Meaning of Localization Industry}

Localization is a product strategy put forward by enterprises to reduce production costs and improve the market competitiveness in the process of international trade for the destination country or region. The localization process of the product includes product design, production, marketing and so on. Localization is divided into many categories depending on the goals, such as localization of market, localization of talents, localization of software, localization of production technology, etc.. In the process of the development of localization industry, the translator is the key to promote enterprises into localization market. Therefore, the good use of translator can help products to adapt to market and help enterprises to occupy the market with the fastest speed, thus getting a rapid development. In order to optimize the development of localized enterprises, a local industry associations was set up, referred to as LISA, in the last century 90's. LISA was set up to help enterprises to complete localized services in international trade, where translation is a very important part of the content.

\section{Introduction of Current Domestic Localization Industry and Translation Market}

\section{Situation of Localization Industry}

The concept of localization industry is proposed by John who is a British economist. This theory is conducted first in the developed countries, meanwhile, the introduction of this concept is not too late by China, but the development process is limited. At present, China advocates "The Belt and Road" economic policy, so that localization industry has a new opportunity. 
The current domestic localization industry has begun to take a certain scale and the entire process is complete. The members of market supply chain are composed of enterprise human resource management, localized service providers, customers and industry tools developers. There are lots of suppliers and enterprises which have a leading global level in market localization, talent localization and software localization, which has a large number of qualified translators, and this figure will also gradually increase with the country's economic development. In order to promote localization industry and improve the training mechanism and management of translators, China Translation Association of Localization Services Committee was set up in 2009, which is responsible for the needs of translators in the process of localization. The establishment of this association also marked the important role of translation in the localization of development, while showed translators can not be replaced.

\section{The Development of Translation}

The development of translation is accompanied by the prosperity of the international market economy. As a bridge of communication between nationality and national culture, translation is an integral part of our life and work. At present, there are many translation companies in the country, engaged in promoting friendly exchanges at home and abroad. At the same time, international cooperation is getting more and more. After "The Belt and Road" economic policy put forward by China, the West Asia and China began a close exchange. There will be a great need for a large number of high-level translators during this process.

At present, China adopts the model of higher education for the cultivation of translators. The Ministry of Education has vigorously promoted the development of translatology and set up a master's and doctorate degree in translatology in many foreign language colleges in China. As an independent subject, language translation is increasingly recognized. In order to further improve the comprehensive level of China's translators, China's Ministry of Education has also introduced a number of educational measures for translation subject. From the curriculum to the management of teaching materials, and then to the training of students thinking, every step is for training high-quality translators. At the same time, this is to promote the further development of Chinese economy.

\section{The Requirements of Translators Based on the Localization Development}

\section{Work Content and Requirements of Localized Translation}

In the localization industry, it will involve a lot of users who use computer to transmit documents and software. These documents appear in the transaction process need to be translated, which is the main content of localized translation. Localized translation is distinguished and defined as before, during and after. English is the most involved according to the localization of the language translation, so the following will take English as an example.

At present, domestic mature localized enterprises will divide its project into several parts, and each stage requires the participation of translators. During the start-up stage of the project, enterprises should summarize the information of the customer, determine the project demand and build the implementation team and so on. Translators need to carry out targeted information search based on the target customer's country. At the project planning stage, it involves the offer, the implementation of the project, etc.. Translators need to translate the document according to the language of the target country. At the project implementation stage, translators need to finish the translation and proofreading of relevant content. At the project ending part, translators need to summarize and backup the project file.

In the process of localization translation, each of the translated documents is intended for the customer or the target population, so the translators have a higher demand. Localized translators need to have a good command of English proficiency and translation skills, be able to skillfully use 
the computer translation tools and finally master a certain organizational skills and have a team spirit.

\section{Personal Literacy and Professional Translation}

Localization industry requirements for translation have a high level of professionalism, but also should have good professional skills. With the advent of the network information age, computers have played a vital role in the localization industry, which replace a lot of traditional mechanical operation process, improve the efficiency of work and reduce the output of the labor. Meanwhile, in the localization industry, involving a lot of industrial words, it also need computer software to assist the completion of the translation. At present, the most common translation software is Taduo Si (SDL Trados) in the localization industry translation. It can use the computer preset program to match automatically the repetitive translation content and retrieve from the memory, which greatly improves the efficiency of translation.

\section{Put Forward Cultivation Strategy of Translators Based on Localization Industry}

After summarizing the enrollment situation of translation subjects in colleges and universities, it is found that with the increase of international trade in recent years, the demand of translators is gradually increasing, which make it a popular subject. In order to meet the high-quality needs of translators, many domestic foreign language colleges begin to set up Master and Doctor degree in translation, meanwhile, translation education is also developing towards the highest professional level. In order to promote the progress of the localization industry, the following are some recommendations based on some colleges have no good methods to cultivate translators.

\section{Clear Target to Cultivate Professional Translators}

Localization industry has been established in China and has some market already, so the demand for translators is very large. However, there is a large lack of cultivation of localization professional translators. In many international developed countries, institutions of higher learning set up specialized courses targeted for the localization and a related degree to provide systematic training programs, while this has not yet developed in our country.

The curriculum setting of Translators' cultivation in the localization industry should be based on market. The training includes professional knowledge of translation and basic industry knowledge. This curriculum can let students have a perfect understanding of translation under the premise of knowing market well, so that they can learn the basic theory and professional knowledge easily. With reference to foreign teaching system, professional education can start from the project management, the use of localization tools, processing of localization software, international programming and other aspects. The more localization translation software students master, the better they adapt to the market.

\section{Schools and Enterprises Work Together to Provide Opportunity}

The purpose of higher education for students is to learn more knowledge to meet the needs of the market, so how to cultivate practical talents has become the teaching goal of universities. With the rapid development of localization industry, the demand for practical talents also increase. Therefore, institutions of higher learning have also begun to find new ways of teaching. Schools and enterprises cooperation put forward based on the localization industry, which can cultivate practical translators. Schools and enterprises reach a cooperation agreement first, and then schools will send students who have professional knowledge of translation to corporation. Therefore, students can really participate in each project, experience translation needs of different stages and practice professional knowledge.

Schools and enterprises cooperation can also enrich the practical courses in addition to providing students with practical positions and opportunities. There are many experienced translators in cooperative enterprises. Schools can hire them as a practical teacher, and then teachers train different levels of students regularly to enhance their translation level. At the same time, teachers 
can list typical cases and analyze with students together to enhance students' understanding of localized industry translation and translation experience. Finally, the performance of students in the classroom will be summarized into the student's assessment to make a comprehensive evaluation of student's academic performance.

\section{Union of Colleges and Universities to Share Excellent Teachers}

There are a lot of colleges and universities have translation major, but most of them are not professional, in addition to professional foreign language school. Most universities set up translation major based on English. Besides, professional courses are not perfect and lack of excellent teachers. In order to make the translation of colleges and universities to get a better development, colleges and universities can integrate their own strength together. Learn from foreign universities successful stories and experience to set translation courses based on the domestic localization market. And then integrate excellent teachers and take the way of teaching tour to improve the teaching level of translation. Finally, colleges and universities can improve students' translation level in this way.

\section{Conclusion}

In the process of the development of localization industry, the translator is the key to promote enterprises into localization market. Therefore, the good use of translator can help products to adapt to market and help enterprises to occupy the market with the fastest speed, thus getting a rapid development. In order to promote localization industry and improve the training mechanism and management of translators, China Translation Association of Localization Services Committee was set up in 2009, which is responsible for the needs of translators in the process of localization. The establishment of this association also marked the important role of translation in the localization of development, while showed translators can not be replaced. At present, China adopts the model of higher education for the cultivation of translators. The Ministry of Education has vigorously promoted the development of translatology and set up a master's and doctorate degree in translatology in many foreign language colleges in China. As an independent subject, language translation is increasingly recognized. In the process of localization translation, each of the translated documents is intended for the customer or the target population, so the translators have a higher demand. Localized translators need to have a good command of English proficiency and translation skills, be able to skillfully use the computer translation tools and finally master a certain organizational skills and have a team spirit. Finally, put forward cultivation strategy of translators based on localization industry to help the current domestic translation to have a professional and orderly development.

\section{References}

[1] Chuanying Wang and Qiliang Cui. The Requirements of Localized Industry Development for Vocational Translation Training and Practice Certification [J]. Chinese Translation, 2010, 04: 76-79+95.

[2] Xiaoxian Zhou. Domestic Localization Industry Development and Career Localization Translators Training [J]. Journal of Changchun University of Technology (Social Science Edition), 2012, 02: 144-146.

[3] Xiaoxian Zhou. The Requirements of Translators for the Development of Localization Industry [J]. Journal of Nanchang College of Education, 2012, 09: 169-170.

[4] Jiaying Ma and Jie Zhang. Study on the Development of Localized Industry and the Strategy of Localized Translators Cultivation [J]. Shaanxi Education (Higher Education Edition), 2013, Z1: 77-78.

[5] Xiwen Wu. Study on Localized Translation Teaching [D]. Nankai University, 2009. 
[6] Lili Qiu. Study on the Cultivation of Localized Translators [J]. Journal of Huaihai Institute of Technology (Humanities and Social Sciences), 2013, 21: 81-83.

[7] Meiyan Lu. Study on the Cultivation of Applied Localized Translators [J]. Journal of Jinhua Vocational and Technical College, 2016,02:24-27. 